\title{
A Qualitative Evaluation of Recovery Processes Experienced by Mentally Disordered Offenders following a Group Treatment Programme
}

Colquhoun1, B

http://hdl.handle.net/10026.1/12180

10.1080/24732850.2018.1510280

Journal of Forensic Psychology Research and Practice

Taylor and Francis

All content in PEARL is protected by copyright law. Author manuscripts are made available in accordance with publisher policies. Please cite only the published version using the details provided on the item record or document. In the absence of an open licence (e.g. Creative Commons), permissions for further reuse of content should be sought from the publisher or author. 
Journal of Forensic Psychology Research and Practice (2018).

Accepted 01/08/2018

DOI: https://doi.org/10.1080/24732850.2018.1510280

A Qualitative Evaluation of Recovery Processes Experienced by Mentally Disordered Offenders following a Group Treatment Programme

\author{
Beth Colquhoun ${ }^{1,2}$ \\ Alex Lord ${ }^{2}$ \\ Alison M. Bacon ${ }^{1}$
}

${ }^{1}$ School of Psychology, University of Plymouth, Plymouth, UK
${ }^{2}$ Department of Psychology, Broadmoor Hospital, Crowthorne, UK

Corresponding author:

Dr Alison M. Bacon

School of Psychology

Plymouth University

Drake Circus

Plymouth PL4 8AA

Tel: 01752584805

Fax: 01752584808

Email: ambacon@plymouth.ac.uk 


\begin{abstract}
This study presents a qualitative, user-focused evaluation of a three-day dramatherapy workshop run as part of an 18-week treatment group for mentally disordered sexual offenders (MDSOs). The programme is based in the Good Lives Model and aims overall to increase empathy, victim awareness and emotional awareness. The objective of the present study was to understand offenders' lived experiences of the workshop and how they perceived it to contribute to their recovery. Semi-structured interviews were conducted with five offenders and their narratives transcribed. An Interpretive Phenomenological Analysis, revealed four superordinate themes which we have termed Not being the person I was, Gaining new perspectives, Social Relationships and Barriers. These themes lend support to recent research on treatment and behaviour change in sexual offenders emphasising responsivity and process issues. This study draws particular emphasis to the need to encourage group cohesion and trust, and highlights issues relating to peer comparisons which may impede new perspectives on personal identity and rationale for change. The study also found barriers to change in some participants including impression management, memory problems and varying levels of attraction or, conversely aversion, to dramatherapy techniques. Practical implications for the effective delivery of sex offender treatment groups in the context of personal recovery from mental disorder and offending are discussed.
\end{abstract}

Keywords: Good Lives Model; mentally disordered sex offenders; recovery processes; IPA; dramatherapy

Funding details: There are no funding details to report for this research

Conflict of Interest: None of the authors have any conflict of interest to disclose. 


\section{Introduction}

In recent years there has been increasing interest in forensic therapeutic process and the means by which sexual offenders make sustainable changes in offence-related behaviour. The Good Lives Model of Offender Rehabilitation (GLM; Ward and Stewart 2003) has gained recognition as a responsive, process-sensitive approach for engaging and motivating sexual offenders with complex needs and facilitating recovery from an offending lifestyle (Purvis, Ward \& Willis, 2011; Willis, Ward \& Levenson, 2014; Willis, Yates, Gannon, \& Ward, 2013). As a rehabilitation framework, the GLM is receptive to offenders' individual interests, abilities, and aspirations. It encourages the construction of intervention plans that support offenders in acquiring the tools to make their own way in the world, achieve outcomes that are personally meaningful to them and meet their underlying needs or "primary goods" in ways other than by offending. The present study focusses on working with mentally disordered sex offenders (MDSOs) where recovery encompasses not only the regulation of offending behaviour but also restoration of mental health and social functioning - collectively termed 'secure recovery' (Drennan \& Alred, 2012; Lord, 2016). This conceptualisation of recovery shares commonality with the GLM as applied to MDSO offending treatment (Barnao, 2013). Sexual offenders with mental disorders are more likely to make a sustained, non-offending recovery if they relate prosocial means of attaining their 'primary goods' to the wider task of developing personal strengths while accommodating the potentially debilitating effects of their mental disorders (Lord, 2016).

Interventions with MDSOs have frequently employed the well-established Risk-NeedRecovery (RNR) model (Andrews \& Bonta, 2010; Bonta \& Wormith, 2013) which applies three core principles: matching of program intensity to offender risk level, targeting of criminogenic needs that are functionally related to criminal behaviour, and matching intervention to the offenders learning style and abilities. There is considerable evidence that 
this approach can reduce recidivism in sex offenders (Andrews \& Bonta, 2010; Hanson, Bourgon, Helmus, \& Hodgson, 2009; Canales, Campbell, Wei \& Totten, 2014). The GLM has been developed as complementary in its approach in that it acknowledges risk factors, whilst also taking a strongly restorative approach, focussing on motivational and engagement issues that are not always resolved in RNR- based treatments (Willis et al, 2013). In inviting an individual to consider how offending behaviour might be an attempt to meet underlying needs and in accepting the basic human need for a satisfying life and achievement of rewarding goals, GLM allows offenders to develop a life-plan for the future. Lord (2016) argues that GLM responds to the specific challenges to recovery and treatment compliance in MDSOs, which are often linked to their disorder as much as their offending behaviour. Although Andrews et al (2011) have argued that the GLM has insufficient focus on risk, they do acknowledge that its strengths-based approach allows a focus on the positive features of the offender's personal makeup and offers a safe, respectful, and honourable space in which recovery can occur. In the present study, we present a qualitative user-focussed evaluation of a MDSO treatment intervention based in the GLM model.

Qualitative and phenomenological approaches to understanding the experience of interventions with sexual offenders has explored perceptions of group processes and what helps or hinders change (Clarke, Tapp, Lord \& Moore, 2013; Walji, Simpson \& Weatherhead, 2014). While there has been much discussion about the need for nurturing but task-focused group facilitation styles that encourage engagement (Sandhu \& Rose, 2012; Serran \& Marshall, 2010), there has been relatively little empirical research on treatment interventions and associated recovery pathways from the offender's perceptive. A systematic review conducted by Bilby, Brooks-Gordon, \& Wells (2006) highlighted that because there are so few accounts of treatment programmes from users themselves it is difficult for practitioners to gauge impact. A growing emphasis on participant perspectives reflects a philosophical belief that consultation 
and user involvement have the potential to increase the quality of outcomes (Barnett \& Mann, 2011). Most recently, Walji, et al (2014) highlighted five key aspects which impact recovery in non-mentally disordered sex offenders; incentives and inhibitions to engagement, pros and cons of group treatment, perspectives of abused and abuser as a basis for transformation, dealing with distress and difficulties in putting plans into action on re-entry into the community. Walji et al reinforce the importance of further qualitative work to explicate userexperiences of treatment programmes. As Clarke et al (2013) have argued, qualitative enquiry is particularly beneficial in this context because it focusses on the personal lived experiences of participants and the convergences and divergences between them. This richness of experience is most readily captured through talk, rather than through quantitative data, such as that obtained from questionnaire responses. The present research addressed these issues in the context of understanding the experiences of MDSOs (a population with especially complex needs) who had undertaken a treatment programme employing the Good Lives philosophy. The aims of the study were twofold: firstly, to gain insight into the understanding and experience of recovery for the MDSOs, and secondly to use this understanding to highlight some practical implications which can inform effective delivery of MDSO treatment groups.

\section{Method}

\section{The Sex Offender Programme}

The intervention evaluated in this study comprised an 18-month treatment group delivered within a secure forensic hospital in the UK holding offenders detained under the Mental Health Act (HMSO, 2007). As in other well-established sex offender treatment programmes, the aim is to prevent future offending and this is the fundamental reason for referral. More specifically the programme targets offence-supportive thinking and impulsivity; aims to improve problem-solving, perspective taking skills, moral reasoning and to raise 
awareness of the impact of sexual offending. To meet the criteria for the programme, patients must have been convicted of at least one sexual offence, or an offence with a clear and established sexual motivation (Clarke et al, 2013). The programme comprised a weekly twohour cognitive-behavioural group-work intervention and an intensive three-day dramatherapy workshop in in week 12 of the programme. It was experiences of this workshop in particular which was the principle focus of this research.

Dramatherapy is the intentional use of drama and/or theatre processes to achieve therapeutic goals. It allows for a dynamic and physically expressive use of metaphor to access emotional and psychological issues in such a way that the actor is distanced from the reality of them and can thus find them easier to tolerate and examine (Jones, 2002). These techniques are used increasingly in sexual offender treatment as an alternative to didactic presentation followed by discussion that is typical of traditional therapy groups (Mann, Daniels \& Marshall, 2003). This dramatherapy component was facilitated by a qualified therapist and aimed to use techniques such as role-play, enacting narratives, guided reflection, 'sculpting' perspectives, observation and commenting on others. In terms of the GLM, these activities aim to increase emotional awareness in terms of both the self and others. Offenders who are emotionally inhibited find it particularly difficult to engage in treatment or to understand their offending in terms of the acquisition of primary goods. Within dramatherapy, an emphasis on personal responsibility for thoughts emotions and motivations and behaviour can chip away at the defence mechanisms that many sex-offenders hide behind and hence relieve cognitive dissonance (the differences between image presented to the world and inner feelings). Sex offenders often have very rigid beliefs and attitudes towards their behaviour which are not conducive to recovery or a health life. Dramatherapy can help to support the changing of such beliefs and the revelation/acknowledgment of the real self, giving both offender and therapist something authentic to build on. Dramatherapy also aims to build therapeutic communities 
amongst the group through a culture of mutual support, consciousness raising and dramatic relief. This can be particular value with sex offenders because sexual offending is an interpersonal behaviour and offenders tend to demonstrate pervasive deficits within their interpersonal relationships (Jennings \& Sawyer, 2003; Marshall, Anderson, \& Fernandez, 1999). Increasing tolerance of group settings, sharing coping strategies and the development of relatedness are all intrinsic to dramatherapy. These can help to address symptoms such as emotional dysregulation, social isolation and delusional beliefs often observed in MDSOs (Willis, et al, 2013; Lord, 2016).

\section{Participants}

Ethical approval was obtained from the research and development department at the hospital, the NHS Research Ethics Committee and University Faculty Ethics Committee. Participants were recruited from patients at the hospital, all of whom are male and aged over 18. To be eligible for the research, participants must have completed the Sex Offenders Group including the dramatherapy component, be deemed as having the capacity to consent to taking part, as determined by their Responsible Clinician, and be able to speak English well. Permission to approach patients was sought from the Responsible Clinician and his/her team in the first instance. Seven potential participants were identified and approached by the team psychologists who explained that a researcher would be coming to speak to them within the next week about taking part in research being carried out within the hospital. If the patient did not wish to take part, they could decline at this stage. Five agreed to take part. The researcher (first author) met with them at a mutually agreed time to discuss the research and issue a written information sheet reiterating the nature of the study, that participation was voluntary and the right to withdraw. Patients then had a further week to decide whether they wished to participate and five chose to do so. All had completed the group within the previous three 
months. Additional demographic, forensic and clinical characteristics of participants were obtained from hospital case files (with permission) and are presented in Table 1. Although their mental disorders were seen as relevant in terms of setting conditions (e.g. substance misuserelated disinhibition, psychiatric medication non-compliance and social exclusion), none of these psychiatric syndromes were assessed as being direct antecedents of the index offences. All of the participants were being treated with psycho-active medication prescribed independently of this programme by their respective consultant psychiatrist.

Table 1. Participant Information

\begin{tabular}{|c|c|c|c|}
\hline Pseudonym & Main ICD-10 Diagnosis & Victim & Forensic History \\
\hline John & $\begin{array}{l}\text { Paranoid schizophrenia } \\
(20.0) \text {; Asperger's } \\
\text { syndrome (84.5) }\end{array}$ & Unknown adult & $\begin{array}{l}\text { Long periods of } \\
\text { hospitalisation }\end{array}$ \\
\hline Chris & $\begin{array}{l}\text { Paranoid schizophrenia } \\
(20.0) \text {; Paranoid } \\
\text { personality disorder }(84.5)\end{array}$ & Known adult & $\begin{array}{l}\text { Periods of } \\
\text { hospitalisation }\end{array}$ \\
\hline Steve & $\begin{array}{l}\text { Anxious/avoidant } \\
\text { personality disorder (60.6) }\end{array}$ & Unknown child & No prior history \\
\hline Mike & $\begin{array}{l}\text { Paranoid schizophrenia } \\
(20.0)\end{array}$ & Known adult & No prior history \\
\hline David & $\begin{array}{l}\text { Paranoid schizophrenia } \\
(20.0) \text {; Asperger's } \\
\text { syndrome (84.5) }\end{array}$ & Unknown child & $\begin{array}{l}\text { Long periods of } \\
\text { hospitalisation }\end{array}$ \\
\hline $\begin{array}{l}\text { The participa } \\
\text { sustained em } \\
\text { misuse. }\end{array}$ & $\begin{array}{l}\text { were British and aged b } \\
\text { yment or in long term re }\end{array}$ & $\begin{array}{l}\text { een } 25 \text { and } 50.1 \\
\text { onships. All had }\end{array}$ & $\begin{array}{l}\text { e had ever been in } \\
\text { tories of substance }\end{array}$ \\
\hline
\end{tabular}




\section{Design and Procedure}

Clarke et al (2013) have stated how qualitative narratives can provide invaluable evidence about the impact of group-work for patients with serious offence histories and qualitative methods have been used effectively in previous peer-reviewed research into offender experiences and treatment programmes (see for instance Walji, et al's, 2014 review). For the present study, a semi-structured interview schedule was developed according to the principles recommended by Smith, Flowers and Larkin (2009) who recommend the use of very open formulations which do not carry assumptions about participants' experiences or lead their responses. In line with their recommendations, interviews began with an open question which invited participants to simply describe what they remembered about the dramatherapy workshop, designed to get them talking and reflecting. Interview questions were deliberately open-ended, encouraging reflection on the workshop in terms of what was helpful or unhelpful with regards to the participant's recovery including relevant emotions, beliefs and perceptions of self and others. This provided a framework while allowing individual participants the freedom to elaborate and expand on aspects most salient to them. As such the interview becomes a collaborative process constructed jointly between researcher and participant, rather than simply a process of data gathering from a passive subject. Questions concerned the issue of recovery within the context of participants' experiences of the treatment group. For instance, participants were asked to describe their general feelings and experiences at the time of the workshop as well as being prompted to describe their ongoing experience. Questions included how the workshop group had helped them to learn about themselves and the ways in which they felt the experience had supported recovery from issues which had led to their incarceration. If participants seemed unsure of what was being asked they were prompted to describe any new skills, their outlook on life, how they felt or to discuss specific memories of the group or dramatherapy exercises they had taken part in. Participants were interviewed 
individually by the first author. Interviews lasted around one hour, were recorded on a standard Dictaphone and transcribed verbatim.

\section{Analysis}

Interpretative Phenomenological Analysis (IPA) allows for an in-depth exploration of experiences of participants who form a relatively homogenous sample in terms of the phenomena of interest (Smith, et al, 2009). The IPA method was selected for its flexibility in theoretical framework permitting a bottom-up approach to determining themes from the data. This is in contrast to alternative qualitative analytical methods that can impose theoretical assumptions about the reality of personal experiences or are designed to generate new theory for further quantitative testing (Glaser, 1992). IPA adopts an ontological approach, suggesting that participants' talk is representative of their psychological world and that they are the experts in their own experiences. How individuals make meaning from their world is explored and a double hermeneutic stance taken in that IPA acknowledges the interpretative role of the researcher in attempting to make sense of the participant's attempts to make sense of their own experiences (Smith et al., 2009). Analysis aims to discover emergent themes in the data to inform the research aims. We used a traditional paper-based method and, in line with the process suggested by Smith et al. (2009), repeatedly worked through the corpus of data to identify recurrent themes. This process comprised four stages: (1) reviewing data in the first transcript, compiling a list of issues relevant to our research questions and noting where in the transcript supporting evidence could be found; (2) reviewing subsequent transcripts in the same way, adding new issues to our list, or new evidence in support of those highlighted previously; (3) repeating the process for all transcripts; (4) clustering related issues into themes. Transcripts and themes were examined independently by the authors to ensure that the emergent themes were sufficiently representative of the issues included and distinctive in their 
own right. By its very nature, this process was not statistically-driven and may have been open to a degree of subjectivity although each of the research team was satisfied that the data had been captured with acceptable parsimony and face validity. It is acknowledged that there may be issues of response bias insofar as, whatever the procedural independence of the interviewer, participants may have perceived her as part of the wider treatment process, tailoring their comments to what they perceived as the desired outcome of a cognitive-behavioural, implicitly rational and personally evaluative clinical intervention (Golafshani, 2003). However, it is important to note that in adopting a position that assumes the reality and value of personal experiences, IPA methods abrogate the need to investigate potential fallibility or subjectivity of responses. IPA supports a focus on fewer participants examined in greater depth, rather than a more superficial analysis of many individuals (Hefferon \& Gil-Rodriguez, 2011; Smith et al., 2009). Our sample was sufficient to identify recurrent themes and divergences across participants, while also balancing the need to preserve the strongly ideographic nature of the data. The results below discuss four key themes which emerged: No longer being the person I was, Gaining new perspectives, Social Relationships, and Barriers. Direct quotes from participants' talk are provided to support verifiability (Murphy, Dingwall, Greatbatch, Parker, \& Watson, 1998). Use of ellipsis (...) indicates pauses or further speech between quotes.

\section{Results}

\section{Not being the person I was}

All five participants expressed treatment as being a fluid, ongoing process which takes into account past, present, and future. Participants demonstrated a level of understanding into the factors that contributed towards both their offence, and subsequent admission to hospital. They were reflective about where they went wrong in the past, demonstrating considered thought for reducing the risk of recidivism and relapse. For instance, John: 
I was able to understand what it was that brought me here and more importantly how to avoid it in the future

Rather than just thinking about his offence, John was beginning to consider wider aspects of his background. He was able to identify triggers for offending behaviour and barriers to change and use this insight in his recovery. Steve shared a similar outlook:

Every time I see that stuff coming again I divert it away so I can continue not being the person I was

Steve uses imaginary markers to determine how far is 'too far', and has been able to think about which behaviours will be unhelpful for him, Indeed, research has illustrated that establishing the triggers and reasoning behind offences enables enhanced insight into potential risk factors, allowing offenders to strategically determine how to prevent recidivism (Colton, Roberts, \& Vanstone., 2009; Grady \& Brodersen, 2008). In turn, it can be argued that this imbues a sense of autonomy for patients and allows them to have a positive outlook, both of which are consistent with the GLM (Willis et al., 2013). The majority of participants acknowledged that there was a need to recover, and spoke about taking each day as it comes, e.g. Mike:

I don't want to recover to where I was before, I don't want to regain anything that I lost, I want to advance with who I am and progress and do better in the future

Whilst Mike stated that he had been in the hospital for seven years, he had not reached a level that satisfied him in terms of 'recovery'. For him, it was not about reverting back to the person he was prior to his offence, but rather seeing his current state as a foundation to 
gradually build upon and improve over the years. David also acknowledged the need to build upon his current attributes:

$$
\begin{aligned}
& \text { It's [learning] what brought me here and what, what I need to change } \\
& \text { and what I need to leave in the past and what I need to take with me, } \\
& \text { you need to bring some stuff with you }
\end{aligned}
$$

David seems to be suggesting that recovery is a dynamic process which does not simply consist of banishing his past and starting again. He is able to ascertain positive characteristics that he knows are helpful and that he would like to retain, whilst there are others that he would prefer to leave behind or change.

\section{Gaining new perspectives}

All five participants further identified with gaining a new perspective having completed the dramatherapy workshop in particular. David connected with the kinaesthetic delivery of the programme:

In dramatherapy we're actually acting and doing things so it kind of makes you think different, not just saying it. Sometimes you say things and not actually mean it but acting it you take it, you take it in a different light

Through engaging in drama, David was able to access emotions and thoughts beyond what he has experienced during previous interventions. He found role-play to be a multifaceted activity in which tone and expression needed to be considered besides content, subsequently enhancing his learning and insight. John also referred to a new outlook on his offending. 
That [dramatherapy] shone a light in a direction that I hadn't really considered before

The metaphoric reality enacted within dramatherapy groups is designed to support perspective-taking and sensitivity to boundaries and alternative interpretations of events (Clarke et al, 2013; Moore \& Ramsden, 2012). This certainly seems to have been effective here. Grady \& Brodersen (2008) have suggested that gaining new perspectives on offending behaviour and related cognitions can foster an increase in self-awareness, or development of a new self-concept along with enhanced self-confidence and concern for others. Again such advances in personal development can support a life where needs are met in prosocial ways - in line with the GLM notion of non-offending means of attaining primary goods (Willis, et al, 2013). As John describes, recovery is a work in progress:

It's a learning curve, but it's improving

\section{Social Relationships}

Participants tended to consistently recall the importance of social relationships. Several comments referred to the importance of forming and maintaining cohesive, genuine relationships with others. When asked about the factors that contributed to his recovery, Chris was quick to refer to the importance of a stable network of relationships, both with the staff in the hospital and with his family, outside:

If I've got something that's bothering me, to tell the staff, to work with the staff so they can try and help me, um, I've learnt that a strong family support unit is important. Relationship between me and my, my two sons, that's important 
What works within the confines of the hospital has to also be effective in the real world (Walji et al., 2014), and Chris recognises that practicing meaningful social interactions with hospital staff stands him in good stead to realise the positive impacts of similar relationships with loved ones; something he was not as mindful of in the past. However most comments about relationships referred to those within the theory group. We have spit these aspects of the data into two sub-themes, The Problem with Groups and The Goldfish Bowl.

\subsection{The problem with groups}

Whilst participants spoke generally about the helpfulness of connectedness with those around them, this was not so clearly felt when applied specifically to the Sex Offender Group. Mike again:

I mean the problem I have with groups, and the problem I have with doing the work in groups in [the hospital] is that I don't really like any of the other people in the groups

And also Steve,

I don't like interacting with groups of people 'cause I have ... err... social fears

It seems that typically, both Mike and Steve struggle to connect with others; negative past experiences are likely to have led them to feel isolated from other people and reluctant to attempt to engage and maintain cohesive relationships. Steve extends his point further: 
This is a significant comment to make, as generally the human species is considered to be inherently social (Frith \& Frith, 2010). Steve claims to have no desire to interact with peers and staff members within the hospital, feeling that having the capacity to do so is not a privilege or something to be enjoyed. In fact, it appears as though Steve might rather prefer to not have the freedom to communicate. Here, the presence of peers can be seen to be a hindrance rather than a help. Steve's diagnosis of anxious/avoidant personality disorder may contribute to this, raising the issue of whether intensive group therapy is in fact a suitable form of treatment for individuals with certain disorders.

Another recurring issue involved self-other comparisons, particularly among participants who desired inclusion and connectedness within their social interactions. John repeatedly referred to the need to know where he stood in relation to his peers:

You want to know, well am I the worst offender here or am I Joe Average?

John's questioning is key to recognising his identity within the group, which is important to him in terms of steering clear of potential threat:

Kettle called the pot black 'cause you're all in the same boat, the same situation

John felt safety in knowing others had committed similar offences to him. Had he considered himself the 'worst', this may have resulted in him isolating himself from the group or being reluctant to share information about his offence, which could have altered the degree of benefit he gained from the group. The concept of participants comparing themselves to others is consistent with what is known about group dynamics and, at an individual level, social comparison theory. In a study of pro-social behaviour, Frey and Meier (2004) demonstrated that individuals base their own behaviours on perceptions of what is normal in a peer group, 
adjusting their own contributions upwards when they learn that they have under-estimated the pro-social behaviour of comparable others. Here, one would predict therapy group participants to compare themselves with their peer group in terms of the level of effort (e.g. task participation or personal disclosure) that is being made and their impressions of how this is being evaluated - "rewarded" - by group facilitators, adjusting their own efforts up or down accordingly. However, while John was happy to feel similar to his group peers, Mike felt differently:

I don't want to be in the same boat as these people ... What I'd done was much worse than what anyone else had done

Mike appears to be keen to separate himself from his peers, viewing them almost with hostility for having committed offences he considers less serious than his own. His subsequent comment suggests almost a sense of superiority:

they were all sex offenders, I'd actually killed someone so, actually I felt kind of like, well whatever they have to say can't be as shocking as what I have to say ...

Boduszek and Hyland's (2011) model of criminal identity formation suggests that offenders use social comparisons to reinforce pro-offending beliefs and negative judgments about non-offenders. Here, Mike seems to be doing something similar in comparing himself to his peers. Although they are also offenders, he does not seem to identify with them, instead seeing himself as different because he is a "worse" offender. Overt criminal identities can be considered a proclamation of the rejection of lifestyles which are expected under non-criminal social norms (Campbell, 1987) and individuals often describe themselves negatively, in terms of what they lack (or choose to reject). Mike however, appears almost proud of his identity, his 
comment about not wanting to be "in the same boat" a disparagement of the other group members - in a similar way to which one with a criminal identity may disparage those who abide by laws and social norms (Boduszek \& Hyland, 2011). For other participants however, it might be hypothesised that at least some may have been identifying with, and attempting to emulate, the impression management techniques of peers who were role modelling attempts to manage their riskiness. Lord and Willmot (2004) identified a similar process for sexual offenders in group therapy responding to modelling and peer reinforcement in reducing offence denial.

\subsection{The Goldfish Bowl}

This subtheme is also concerned with relationships, but concerns how these are influenced by the "public" nature of the group environment. The theme refers to the idea that patients felt their every action was magnified under the eyes of others present in the group and the effect this had on their feelings of vulnerability or conversely, of trust. As John put it, in dramatherapy:

Not standing out really was the aim

Four out of the five participants expressed a sense of vulnerability when discussing their experiences of the workshop, particularly Steve:

It didn't build my confidence, in fact it had the opposite effect...it knocked my confidence

Steve seemed unable to identify with the process of sharing and experiencing the positive benefits of working within a group, instead feeling overwhelmed by shame and embarrassment. Interestingly, the single activity that was prominent in David's mind is one that 
is referred to as 'the goldfish bowl' in psychodrama (Mann, Daniels \& Marshall, 2003), where he had to speak about how his victim might feel whilst being surrounded by peers.

Speaking about my victim and stuff ... sitting on your own chair, she [the facilitator] was sitting next to me, the group were on the outside watching in, it was quite difficult

It seems that this theme is particularly significant for David, who found the very nature of this exposing challenge helpful in enabling him to heighten awareness for his victim:

It's different to think about it in front of people because I had to pick out the words, and pick out the right words...there ain't no right or wrong answers but I wanted to describe it properly in front of other people, I thought about how she might have felt

Dramatherapy can be effective for MDSOs if they can take risks with their personal material in a safe space surrounded by peers with whom they had grown to trust (Ramsden \& Guarnieri, 2010). Our participants also suggested that trust was a key ingredient of recovery group-work however in several cases feelings of vulnerabilities were exacerbated by lack of trust. Mike expressed wariness concerning his peers:

I found it more difficult because I didn't trust the other people in the group so found it quite hard to do drama with them

Despite having widely used drama throughout his school years and during his time within the hospital, Mike was unable to form trusting relationships with group peers and 
subsequently felt reluctant to share his passion and abilities. Steve's mistrust extended beyond the individuals he shared the workshop experience with:

It felt like it was another way for [the hospital] to humiliate its patients

There is a sense that Steve believes the supposedly therapeutic environment purposefully works to shame patients. It can be inferred that Steve has previously felt embarrassment within the hospital, and this has continued into the workshop. David reflected on a breach of trust when asked to discuss negative workshop experiences:

There was a bit in the group where there was another patient speaking about... um... other people and that outside the group but he got kicked off the group ...I was like, shall I carry on doing the group?

David's comment is in reference to a peer who breached confidentiality within the group. As Walji et al (2014) identified, supportive peer relations are an important factor in the success of interventions. A breach of confidentiality could be seen to damage trust built up by group members, having deleterious effects on treatment effectiveness (Clarke et al., 2013). However, David made the decision to stay, highlighting his understanding that this was an unusual occurrence and that his peers generally could be trusted.

\section{Barriers}

Although all participants consented to being interviewed and were willing to answer all of the questions that were presented to them, three key barriers became apparent: poor memory, impression management and disconnection. We discuss these below. 


\subsection{Poor memory}

Dramatherapy is used as a clinical intervention for patients due to evidence that active learning processes lead to long-term retention (Yaniv, 2011). However, remembering aspects of the group was troublesome for participants during the interviews. Both John and Chris struggled to remember the names of the activities they had engaged in:

Dramatherapy? Was that part of [the group]? We done something called, um... what was it again?

However, although the jargon used by the facilitators was not particularly salient to the participants, when context and prompts were given, they were able to remember. John initially struggled to identify having engaged in dramatherapy, yet was soon able to fluently recall workshop material:

We were discussing the effects of offending and the effect it had on others as well, how we perceive different things from others

Issues of memory and retention have been found to be typical in individuals with chronic mental disorders (Lumsden, Chesterman, \& Hill, 1998) and participants' lack of spontaneous memory for the workshop is a cause for concern. For example, an individual may struggle with the concepts presented in a therapy, or lack the ability to generalize their learning to new areas (Freeman \& McCloskey, 2003). Alternatively, this may be a symptom of avoidance brought about by traumatic events surrounding the offence. 


\subsection{Impression management}

Although it was clarified to the participants that what they said during the interview would not be discussed with their clinical care teams, it still seemed at times that what was said was aimed at creating a particularly positive, or negative, impression to the researcher. In particular, participants frequently stressed how the intervention had worked for them, despite later being unable to recall details of the activities that they had engaged in. Throughout his interview, Chris appeared keen to demonstrate his enthusiasm and compliance, stating that he was excited at the thought of participating in the workshop and that he had no difficulties with the exercises at hand:

It met all of my expectations really, it was better than I, than I thought it was gonna be

Despite being unable to describe a particular activity that he found useful, this comment suggests that Chris' experience was exceptionally positive. Alongside attempts to control the researcher's perceptions of them, participants' comments suggested they had attempted similar impression management during the workshop. David articulated that he was anxious to participate in the role-play, and felt a sense of pressure to behave how he felt he should rather than how he would, had peers not surrounded him:

I thought I was forced to be upset not feel upset you know what I mean, I felt that I should feel upset so I did

This comment suggests that he did not feel a genuine sense of emotion towards his victim, but rather responded in a way that he felt would be expected by facilitators and fellow patients. Steve described a similar experience during his time in prison: 


\section{I had to make up a story that fitted their manual}

This is not simply a matter of not wanting to stand out in the group (as John described previously). While that arose out of self-consciousness (see the Goldfish Bowl subtheme), impression management was aimed at presenting an image of low risk and recovery to the facilitators. Steve and David were aware that their assessed progress in the prison group was likely to affect decisions about their readiness for release, so it was important to be seen to benefit from the experience. Gannon and Polaschek (2005) have reported similarly in terms of sexual offenders under-reporting problems in psychometric questionnaire evaluations related to treatment.

\subsection{Disconnection}

This subtheme illustrates the process whereby a fundamental separation is noted between then and now. Both John and Steve spoke of dismissing their past completely and starting on a clean slate:

I sort of want to put it all behind, leave [the hospital] in the past My past is my past, when I get out of here I'm like a phoenix, no past

As evidenced in Theme 1(Not the person I was), participants expressed an appreciation for learning about what it was that brought them to the hospital and using this to change behaviour in the future. However, the comments above suggest a wish for complete disconnection from their offending, and Steve's choice of the word 'phoenix' signifies his desire for a 'rebirth' from his previous ways. In theme 1 it is notable that participants spoke about the "journey" of recovery in terms of putting the past behind them and Steve commented 
on a wish "not to be the person I was". Strikingly, Steve described a blurring in reality during the time of his index offence:

Before I committed my offence I was living in a fantasy world

It may be that Steve is unclear "who he was" and is so determined to steer clear of the fantasy world he indulged in during his offence that he withdraws from any form of play, or alternative take on reality. Mike shared a similar experience:

I lost sight of the line that separated what happens on stage and what's dramatic from what was happening in my life and what I was actually doing

In Theme 1 both Mike and Steve indicated a wish to leave their past behind and move on away from an offending lifestyle. While this would appear to be a positive intention, here we see an alternative narrative whereby a fear of returning to their past life appears to have created a barrier to moving ahead. In Steve's case, he is highly avoidant of anything which strays from reality and cannot allow himself to engage fully in dramatherapy, fearful that he fall back into the fantasy world he inhabited at the time of his offence. His wish to completely disconnect from that time in his life is perhaps reflective of his diagnosis of anxious/avoidant personality disorder. Conversely, Mike is still very much swaddled in building a dramatic reality and thrives when creating roles for himself. It could be argued that he is still disconnected from real life as much now as when he offended. 


\section{Discussion}

The themes discussed above suggest parallels with Walji et al's (2014) meta-analysis of studies with non-psychiatric sex offenders, particularly in relation to incentives and inhibitions; peers acting as either a help or hindrance; and dealing with distress. However, many of the participants in this study appeared to be distrustful of each other and the facilitators and some were unsure of the explicit purpose of the dramatherapy workshop. Dramatherapy has been found to be effective for MDSOs if they can take risks with their personal material in a safe space surrounded by peers with whom they had grown to trust (Ramsden \& Guarnieri, 2010). This was clearly not the case with some of our participants. Although some found it a very helpful experience in their recovery journey, others admitted to being only superficially engaged with limited recollections and one person, in particular, found role play humiliating.

Accounts of the secure recovery process for psychiatric offenders (Drennan \& Alred, 2012; Lord, 2016) indicate that they view their rehabilitation into the community as a process which is ever-changing and gradual in nature. This is highly consistent with the concept of "The Journey to a Good Life" and with the GLM (Barnao, 2013; Willis et al., 2013), as is the notion of finding new meaning in one's mental disorder. Moreover, learning to manage their risk through identifying triggers and boundaries was clearly defined as a specific goal of recovery for participants. The second superordinate theme, "Social Relationships", emphasised the significance of attachment in the process of psychological treatment for MDSOs (Craissati, 2009; Willmot \& McMurran, 2014). It is therefore unsurprising that issues of mistrust emerge, a common maladaptive schema which can raise a barrier to recovery (Szlachcic et al, 2015; Young, Klosko, \& Weishaar, 2003). Clarke et al's (2013) research highlighted the benefit of engaging in therapy alongside others who were in a similar position due to shared experiences, thus reducing feelings of isolation. In the present study however, being observed by staff and 
peers in "The goldfish bowl" and the detection of a sense of cohesion (or not) in the group suggested that for some, relationship was perhaps not generally found, nor sought.

Impediments to recovery were acknowledged in the final theme, "Barriers". One participant in particular found role-play unbearably harrowing and humiliating in front of his peers. The subtheme "Disconnection" further highlighted participants consciously detaching from their previous lives, which at times mirrored a blurring of reality during the period preceding and during their offence. Young et al's (2003) notion of the "detached protector" schema mode might be linked to this process of dissociation, whereby an individual who has suffered abuse and trauma (typical for many sexual offenders) detaches from engaging with or processing emotionally threatening experiences. Overall, these data provide a multi-faceted picture of some of the difficulties and challenges for recovering sex offenders. Webster (2005) highlighted how the complex psychological needs and goals of individual offenders may both enhance recovery, or promote recidivism. The GLM assumes we all have similar needs and aspirations and that criminality occurs when individuals lack the internal or external resources necessary to satisfy these by pro-social means. In other words, criminal behaviour, including sex offending, represents a maladaptive attempt to meet life goals. Burrowes \& Needs (2009) detail barriers to change which are clearly reflected in our data, for instance, the costs of engaging in a rehabilitation program may include a dislike of working in groups, the perceived loss of autonomy, or feeling uncomfortable about talking about offences in front of others. "Performance" in the group may have perceived implications for the likelihood of release, being transferred to a preferable institution or educational or work opportunities within the prison.

\section{Practical Implications}

A tendency to manage impressions others held of them was particularly prevalent across the sample, and it would be reasonable to suggest that there was a tendency towards 
overly positive self-presentation. This is often the case amongst sexual offenders in questionnaire responses too (Gannon \& Polaschek, 2005), as well as with individuals with psychopathic personality traits (Thornton \& Blud, 2007) or low motivation to control their offending (Webster, 2005). While this might be seen as a limitation of this study, it also works to reinforce the importance of such factors in other contexts such as when constructing offender management plans or making discharge or referral assessments.

Especially, but not exclusively with sexual offenders who have a mental, issues of impaired memory and dissociation from therapeutic material needs to be considered (Taylor \& Morrisey, 2012). Given that participants were generally able to reflect on the skills used within the group if prompted, a recommendation for future interventions is to include follow-up work delivered nearer to, or soon after, return to the community, to reduce memory loss and recap on skills. Our data further suggest that the experience of role-play may result in unexpected or iatrogenic consequences. Role-play is regarded as a fundamental component of group therapies and routinely offered. While many graduates of sex offender treatment programmes single out role play as being particularly memorable and powerful (e.g. Clarke et al, 2013), some individuals may also be traumatised by their own offending behaviour, feeling coerced (and therefore humiliated) into displays of behaviour in front of peers and vicarious exposure to others' offending (Levenson, 2014). Additionally, while treatment groups can foster social bonding leading to a willingness to learn, acceptance of role models and commitment to change (Willmot \& McMurran, 2014), our participants were experiencing disorders which manifest in anxious and/or paranoid behaviours and our data suggest that some had difficulty bonding with others in the group and in trusting both them and the facilitators. In clinical practice, it is often observed that offering treatment programmes to individuals with severe personality disorders may not engender total self-insight and immediate self-management strategies but, rather, they sensitise the awareness of supervisors to the range and expression of the underlying disorders 
(Thornton \& Blud, 2007). As such, our second recommendation is that practitioners carefully consider patient suitability and tailor workshops to respond to individual needs, with the aim of reducing deleterious outcomes and barriers to treatment. Finally, the goal of IPA methods is to examine the experience of participants, rather than provide evidence which can be generalised more globally and, as such, there may be a question over the transferability of these results. However, comparability with findings from both qualitative and quantitative research in other settings indicates a level of consistency in the experiences of sex-offenders in groupwork programmes, and a therefore level of robustness to our findings (Bilby et al., $2006 \mathrm{Walji}$, et al, 2014). Nevertheless, our final recommendation is that further work is needed to extend these findings by means of prospective longitudinal research to examine behavioural and attitudinal shifts in the context of the effect of treatment groups on offending pathways.

\section{Limitations}

This study is not without limitations. Firstly, this was a relatively small sample in a cross-sectional rather than longitudinal study. A further issue is that our participants were included in the study by virtue of having a diagnosed mental health diagnosis. We acknowledge that offenders with learning difficulties or Autistic Spectrum Disorders, for instance, are also classed as mentally disordered and were not represented in our sample (though two of our participants did have a diagnosis of Asperger's syndrome). While our findings are salient for the participants in question, we cannot necessarily generalise to all MDSOs some of whom are likely to have very different experiences because of the nature of their disorder. We were unable to be too explicit about participants' disorders for ethical reasons concerning possible identification, though the symptoms experienced across our sample are fairly typical of MDSOs (Lord, 2016). Future resrach might usefully focus on how experiences of dramatherapy can vary according to individual mental health characteristics of patients. 


\section{Conclusions}

Sex offender therapists are uniquely positioned to cultivate a readiness to change within offenders, facilitating increased security within society through reducing recidivism. In order for treatment to be successful, the experiences of those receiving it must be considered. The themes identified in this study throw light on to the processes of change in MDSOs and how their experiences of dramatherapy in particular can influence this. We also offer practical implications to be considered by therapists in overcoming the (substantial) barriers to change in such offenders (c.f. Burrowes and Needs, 2009). From the offender's perspective, embracing genuine desistance from offending is at least as much an emotional as an explicitly rational process and relates foremost to a challenge to the offender's identity, as well as the possible effects of trauma. Trust is also a major issue and it is perhaps unsurprising that some participants will resist engaging too deeply with a challenging process such as role-playing in dramatherapy, while some individuals may find the whole treatment experience threatening and aversive. These findings are important for increasing the body of research around recovery and can inform design, participant selection and delivery of interventions in high security psychiatric hospitals and also form a basis for good practice in lower secure units. 


\section{References}

Andrews, D. A., \& Bonta, J. (2010). The Psychology of Criminal Conduct (5th ed.). New Providence, NJ: LexisNexis Matthew Bender.

Andrews, D. A., Bonta, J., \& Wormith, J. S. (2011). The risk-need-responsivity (RNR) model. Does adding the good lives model contribute to effective crime prevention? Criminal Justice and Behavior, 38, 735-755.

Barnao, M. (2013). The good lives model tool kit for mentally disordered offenders. Journal of Forensic Practice, 15, 157-170.

Barnett, G. D., \& Mann, R. E. (2011). Good Lives and Risk Assessment: Collaborative Approaches to Risk Assessment with Sexual Offenders. In Kemshall, H. \& Wilkinson, B. (Eds.), Key Issues in Risk Assessment and Risk Management (pp.139-154). London: Jessica Kingsley Publishers.

Bilby, C., Brooks-Gordon, B., \& Wells, H. (2006). A systematic review of psychological interventions for sexual offenders II: Quasi- experimental and qualitative data. Journal of Forensic Psychiatry and Psychology, 17, 467484.

Boduszek, D. and Hyland, P. (2011). The theoretical model of criminal social identity: Psychosocial perspectives. International Journal of Criminology and Sociological Theory, 4, 604615.

Bonta, J., \& Wormith, J. S. (2013). Applying the risk-need-responsivity principles to offender assessment. In L. A. Craig, L. Dixon, \& T. A. Gannon (Eds.), What works in offender rehabilitation: An evidence-based approach to assessment and treatment (pp. 71-93). Chichester: John Wiley \& Sons, Ltd.

Burrowes, N., \& Needs, A. (2009). Time to contemplate change? A new framework for assessing readiness to change with offenders. Aggression and Violent Behaviour, 14, 3949. 
Campbell, A. (1987). Self-definition by rejection: The case of gang girls. Social Problems, 34, $451-466$.

Canales, D. D., Campbell, M. A., Wei, R., \& Totten, A. E. (2014). Prediction of general and violent recidivism among mentally disordered adult offenders. Test of the level of service/risk-need-responsivity (LS/RNR) instrument. Criminal Justice and Behavior, 41, 971-991.

Clarke, C., Tapp, J., Lord, A. \& Moore, E. (2013). Group-work for offender patients on sex offending in a high security hospital: Investigating aspects of impact via qualitative analysis. Journal of Sexual Aggression, 19, 50-65.

Colton, M., Roberts, S., \& Vanstone, M. (2009). Child sexual abusers' views on treatment: A study of convicted and imprisoned adult male offenders. Journal of Child Sexual Abuse, $18,320-338$.

Craissati, J. (2009). Attachment Problems and Sex Offending. in A.R. Beech, L.A. Craig, \& K.D. Browne (Eds.), Assessment and Treatment of Sex Offenders: A Handbook. Oxford: Wiley-Blackwell.

Drennan, G., \& Alred, D. (2012). Recovery in forensic mental health settings: From alienation to integration. In G.Drennan \& D. Alred (Eds.). Secure Recovery: Approaches to Recovery in Forensic Mental Health Settings (pp. 1-10). London: Routledge.

Freeman, A., \& McCloskey, R. D. (2003). Impediments to effective psychotherapy. In R. Leahy (Ed.), Roadblocks in Cognitive-Behavioral Therapy (pp. 24-48) New York: The Guildford Press.

Frey, B.S. \& Meier, S. (2004) Social comparisons and pro-social behaviour: Testing “conditional cooperation" in a field experiment. The American Economic Review, 94, 1717-1722. 
Frith, U., \& Frith, C. (2010). The social brain: allowing humans to boldly go where no other species has been. Philosophical Transactions of the Royal Society B: Biological Sciences, $365,165-176$

Gannon, T. A., and Polaschek, D. L. L. (2005). Do child molesters deliberately fake good on cognitive distortion questionnaires? Sex Abuse, 17, 183-200.

Glaser, B. G. (1992). Basics of grounded theory analysis: emergence vs forcing. Mill Valley, CA: Sociology Press

Golafshani, N. (2003). Understanding Reliability and Validity in Qualitative Research. The Qualitative Report, 8(4), 597-606.

Grady, M.D., \& Brodersen, M. (2008). In Their Voices: Perspectives of Incarcerated Sex Offenders on Their Treatment Experiences: A qualitative study. Sexual Addiction and Compulsivity, 15, 320-345.

Hanson, R. K., Bourgon, G., Helmus, J., \& Hodgson, S. (2009). The principles of effective correctional treatment also apply to sexual offenders: A meta-analysis. Criminal Justice and Behavior, 36, 865-891.

Hefferon, K., \& Gil-Rodriguez, E. (2011). Methods: Interpretative phenomenological analysis. The Psychologist, 24, 756-759

HMSO (2007). The Mental Health Act 2007.

https://www.legislation.gov.uk/ukpga/2007/12/contents

Jennings, J. L., \& Sawyer, S. (2003). Principles and techniques for maximizing the effectiveness of group therapy with sex offenders. Sexual Abuse: A Journal of Research \& Treatment, 15, 251-268.

Jones, P. (2002). Drama as Therapy: Theory Practice and Research. New York: Routledge. Levenson, J. (2014). Incorporating trauma-informed care into evidence-based sex offender treatment. Journal of Sexual Aggression, 20, 9-22. 
Lord, A. (2016). Integrating risk, the Good Lives Model and recovery for mentally disordered sexual offenders. Journal of Sexual Aggression. Journal of Sexual Aggression, 22, $107-$ 122.

Lord, A., \& Willmott, P. (2004). The process of overcoming denial in sexual offenders. Journal of Sexual Aggression, 10, 51-61.

Lumsden, J., Chesterman, L.P., \& Hill, G.M. (1998). Neuropsychiatric indices in a high security admission sample I: Estimating the prevalence. Criminal Behaviour and Mental Health, 8, 285- 310 .

Mann, R.E., Daniels, M. \& Marshall, W.L. (2003). The use of role plays in developing empathy. In: Y.M. Fernandez (Ed.), In their shoes: Examining the issue of empathy and its place in the treatment of offenders (pp. 32-48). Oklahoma City: Wood 'n' Barnes.

Marshall, W. L., Anderson, D., \& Fernandez, Y. (1999). Cognitive Behavioural Treatment of Sexual Offenders. Chichester: John Wiley \& Sons Ltd.

Moore, E. \& Ramsden, E. (2012). Groupwork for Offence Perpetrators with a History of Boundary Violation in the Hospital Setting. In A. Aiyegbusi \& G. Kelly (Eds.), Professional and therapeutic boundaries in forensic mental health practice (pp. 63-77). London: Jessica Kingsley Publishers.

Murphy, E., Dingwall, R., Greatbatch, D., Parker, S., \& Watson, P. (1998). Qualitative research methods in health technology assessment: A review of the literature. Health Technology Assessment, 2, 1-27.

Purvis, M., Ward, T. \& Willis, G. (2011). The Good Lives Model in Practice: Offence Pathways and Case Management. European Journal of Probation, 3, 4-28.

Ramsden, E., \& Guarnieri, M. (2010). Dramatherapy and victim empathy: a workshop approach in a forensic setting. In Jones, P. (Eds.), Drama as therapy: Volume 2: Clinical work and research into practice, London: Routledge. 
Sandhu, D.K., \& Rose, J. (2012). How do therapists contribute to therapeutic change in sex offender treatment: An integration of the literature. Journal of Sexual Aggression, 18, 269283.

Serran, R., \& Marshall, W. (2010). Therapeutic process in the treatment of sexual offenders: a review article. The British Journal of Forensic Practice, 12, 4-16.

Smith, J.A., Flowers, P. \& Larkin, M. (2009). Interpretative Phenomenological Analysis: Theory, Method and Research. London: Sage.

Szlachcic, R., Fox, S., Conway, C., Lord. A. \& Christie, A. (2015). The relationship between schemas and offence supportive attitudes in mentally disordered sexual offenders. Journal of Sexual Aggression, 21, 318-336.

Taylor, J., \& Morrissey, C. (2012). Integrating treatment for offenders with an intellectual disability and personality disorder. The British Journal of Forensic Practice, 14, 302-315.

Thornton, D., \& Blud, L. (2007). The influence of psychopathic traits on response to treatment. In H. Herve \& J.C. Yuille (Eds.), The psychopath: Theory, research and practice (pp. 505539). Hillsdale, New Jersey: Lawrence Erlbaum Associates.

Walji, I., Simpson, J., \& Weatherhead, S. (2014). Experiences of engaging in psychotherapeutic interventions for sexual offending behaviours: a meta-synthesis. Journal of Sexual Aggression, 20, 310-332.

Ward, T. \& Stewart, C.A. (2003). The treatment of sex offenders: risk management and good lives. Professional Psychology: Research and Practice 34, 353-360.

Webster, S. (2005) Pathways to Sexual Offense Recidivism Following Treatment An Examination of the Ward and Hudson Self-Regulation Model of Relapse. Journal of Interpersonal Violence, 20, 1175-1196.

Willis, G.M., Ward, T. \& Levenson, J.S. (2014). The good lives model (GLM). An evaluation of GLM operationalization in North American treatment programs. Sex Abuse, 26, 58-81. 
Willis, G.M., Yates, P.M., Gannon, T.A., \& Ward, T. (2013). How to integrate the good lives model into treatment programs for sexual offending: An introduction and overview. Sexual Abuse, 25, 123-142.

Willmot, P., \& McMurran, M. (2014). An attachment-based model of therapeutic change processes in the treatment of personality disorder among male forensic patients. Legal and Criminological Psychology. Online pre-print doi: 10.1111/lcrp.12055

Yaniv, D. (2011). Revising morenian psychodramatic encounter in light of contemporary neuroscience: Relationship between empathy and creativity. The Arts in Psychotherapy, 38, 5258.

Young, J.E., Klosko, J.S., \& Weishaar, M.E. (2003). Schema Therapy: A Practitioners Guide. New York: The Guildford Press. 